\title{
Drug-drug Interactions of Antithrombotic Medications During Treatment of COVID-19
}

\section{COVID-19 Tedavi Sürecinde Antitrombotik İlaçların İlaç-ilaç Etkileşimleri}

\author{
(D) Oğuzhan FIRAT*, (D) Burcu KELLECI ÇAKIR, (D) Kutay DEMIRKAN \\ Hacettepe University Faculty of Pharmacy, Department of Clinical Pharmacy, Ankara, Turkey
}

Key words: COVID-19, antithrombotics, drug-drug interactions

Anahtar kelimeler: COVID-19, antitrombotik ilaçlar, ilaç-ilaç etkileşimleri

\section{Dear Editor,}

Coronavirus Disease-2019 (COVID-19), as an outbreak, is associated with high morbidity and mortality. Since it affects the elderly more than other age groups, intensive care requirement and the risk of cardiovascular diseases and stroke become important due to the wide usage of antithrombotic medication. As a result of potential drug-drug interactions, these high-risk medications may cause gastrointestinal bleeding. ${ }^{2}$ We believe that identifiying drug-drug interactions between COVID-19 and antithrombotic medications, which are commonly used in patients in the intensive care unit who suffer from cardiovascular diseases or stroke, is beneficial to ensure appropriate and safe treatment.

Hydroxychloroquine, a first-line treatment option for COVID-19, has a few drug interactions with antithrombotics. Although hydroxychloroquine does not have any drug-drug interaction with other antithrombotics (such as heparin, enoxaparin, aspirin, clopidogrel, and warfarin), it can increase the blood levels of apixaban (low risk), dabigatran (moderate risk), edoxaban (moderate risk), and rivaroxaban (low risk). ${ }^{3}$

Lopinavir/ritonavir (LPV/r) combination and strong inhibitors of cytochrome P450-3A4 and P-glycoprotein may enhance the blood levels of apixaban (high risk), edoxaban (moderate risk), rivaroxaban (high risk), and ticagrelor (high risk). During concomitant use with LPV/r, it is recommended to adjust the dose of apixaban to $2.5 \mathrm{mg}$ twice daily. Additionally, concurrent use of LPV/r may decrease the serum concentrations of clopidogrel (high risk), dabigatran (moderate risk), dipyridamole (moderate risk), and warfarin (moderate risk). If possible, switching to prasugrel is recommended for patients using clopidogrel with $\mathrm{LPV} / \mathrm{r}^{3}$

Concurrent use of oseltamivir and warfarin (low risk) can lead to increased serum concentration of warfarin; however, this interaction does not require any intervention except monitoring the international normalized ratio. Additionally, clopidogrel (moderate risk) may decrease the serum concentrations of active metabolites of oseltamivir. ${ }^{4}$

In some countires, the use of azithromycin in combination with hydroxychloroquine is the most common approach among treatment options of COVID-19. In case of concomitant use of azithromycin during venous thromboembolism treatment with edoxaban, the serum concentration of edoxaban may significantly increase, which leads to the risk of exceeding its maximum daily dose (30 mg). The use of azithromycin with apixaban (minor risk), rivaroxaban (low risk), dabigatran (moderate risk), or warfarin (moderate risk) may enhance the serum concentration of these antithrombotic drugs. ${ }^{5}$

In terms of interaction with antithrombotics, because of limited data available at the moment, favipiravir seems to be the safest option among other medications used in COVID-19 treatment. The interaction of favipiravir with antithrombotic drugs has not been reported. ${ }^{3}$

*Correspondence: ogzhnfrt@gmail.com, Phone: +90 5414894206 ORCID-ID: orcid.org/0000-0002-8726-8530

Received: 14.09.2020, Accepted: 22.09.2020

-Turk J Pharm Sci, Published by Galenos Publishing House. 
During COVID-19 treatment, concomitant use of high-risk medications such as antithrombotics should be assessed carefully for drug-drug interactions to avoid any negative outcomes in the treatment process.

Conflicts of interest: No conflict of interest was declared by the authors. The authors alone are responsible for the content and writing of the paper.

\section{REFERENCES}

1. Aggarwal G, Lippi G, Michael Henry B. Cerebrovascular disease is associated with an increased disease severity in patients with Coronavirus Disease 2019 (COVID-19): A pooled analysis of published literature. Int J Stroke. 2020;15:385-389.
2. Delaney JA, Opatrny L, Brophy JM, Suissa S. Drug drug interactions between antithrombotic medications and the risk of gastrointestinal bleeding. CMAJ. 2007;177:347-351.

3. Interactions with Experimental COVID-19 Therapies, Liverpool Drug Interaction Group, 2020. (Accessed March 13, 2020 at https://www. covid19-druginteractions.org/)

4. Drugs.com [Internet]. Oseltamivir Drug Interactions from Drugs.com; c1996-2020 [Updated: 10 April 2020; Cited: 27 April 2020]. Available from: https://www.drugs.com/drug-interactions/oseltamivir.html

5. Azithromycin. In: Lexi-drugs online [database on the Internet]. Hudson $(\mathrm{OH})$ : Lexicomp, Inc.; 2020 [accessed 27 April 2020]. Available from: https://www.uptodate.com/contents/azithromycin-systemicdrug-information?search=azithromycin\&source=panel_search_ result\&selectedTitle=1 145\&usage_type=panel\&display_rank=1 